\title{
Towards a New Monetary Policy Regime in Mozambique
}

\author{
Ari Aisen \\ International Monetary Fund \\ Félix Simione \\ International Monetary Fund
}

We document the main features of the current monetary policy regime in Mozambique, describe ongoing structural policy changes, and analyze the main challenges facing the central bank in the process to modernize its monetary policy framework. The paper focuses on the needed reforms to successfully replace monetary aggregates by interest rate as the main instrument of monetary policy. Deepening the understanding of the monetary transmission, further building inflation forecasting capacity, strengthening the coordination between fiscal and monetary policies, enhancing communications and modernizing the legal framework to ensure central bank operational autonomy are essential to the success of the new monetary regime.

Keywords: Monetary Policy Regimes, Monetary Transmission Mechanisms

\section{INTRODUCTION}

Many central banks in low-income countries (LICs) in Sub-Saharan Africa are modernizing their monetary policy regimes. The role of monetary policy in LICs has been a controversial topic. Mishra et al. (2012), for example, argue that the weak institutional framework prevalent in LICs drastically reduces the role of securities' markets rendering traditional monetary transmission mechanisms using market interest rates and market-determined asset prices weak and unreliable. However, Berg et al. (2013) based on event studies applied to four Sub-Saharan economies (Kenya, Rwanda, Tanzania and Uganda) found that the transmission mechanism is effective with large policy-induced changes in the short-term interest rates strongly transmitting to market interest rates, exchange rates, output and inflation. The transmission occurred even though, like in other LICs, the four countries have relatively small, concentrated and bankdependent financial systems. The authors observed that monetary transmission was stronger in Kenya and Uganda. In the first case, the authorities explicitly signaled the monetary policy stance with a short-term interest rate and described their intentions in terms of an inflation objective. In the case of Uganda, the inflation targeting lite regime seemed simpler and more transparent.

The initial success with modernizing monetary policy frameworks in some central banks in SubSaharan economies has attracted the attention of other central banks in the region, including that of Mozambique. Moreover, the economic crisis that engulfed Mozambique in 2016, required an effective 
and credible policy response that would contain the escalating inflation and help stabilize it by anchoring economic agents' inflation expectations.

In considering Mozambique's experience, we examine both its old and new monetary policy regimes and frame the analysis with the recent thinking in the field as documented in the International Monetary Fund's framework on evolving monetary policy regimes. We explore time series data obtained from the Bank of Mozambique and Mozambique's National Institute of Statistics, compute standard indicators in the monetary policy literature, and review the Bank of Mozambique's legal framework to support the key conclusions of the paper. The remainder of the paper is as follows. Next, we document the recent transition process of the monetary policy regime in Mozambique. Later, we discuss the way forward and the policy challenges inherent to this transition. Finally, we conclude and discuss some policy implications emerging from the analysis.

\section{MONETARY POLICY REGIME TRANSITION: THE MOZAMBICAN CASE}

\section{The Old Regime}

Up until April 2017, Mozambique's monetary policy framework was exclusively targeting monetary aggregates. The main de jure objective of the Bank of Mozambique (BM) was to preserve the value of the national currency, with reserve and broad money serving, respectively, as the operating and the intermediate targets. Under this regime, the money multiplier and velocity were assumed to be stable and predictable, while exchange rates were freely determined, with BM intervening only to smooth excessive exchange rate volatility (Bank of Mozambique, 2017). Two interest rates were used to aid reserve money targeting and help communicate the monetary policy stance- the standing lending facility (FPC) and the deposit (FPD) interest rates. These defined an interest rate corridor within which interbank market rates usually fluctuated. Open market operations through T-bills and repo issuances, combined with an interest rates' corridor, were primarily aimed at containing reserve money below a given targeted ceiling. In most cases the monetary-based framework was not aligned with the standard seven principles of monetary policy outlined in the 2015 IMF Board paper on evolving monetary policy frameworks in LICs. We provide a brief discussion of these principles below.

\section{Principle I: Clear Mandate and Operational Independence of the Central Bank}

The BM mandate entailed some ambiguity. As stated in the BM Law 01/92, the BM main objective was the "preservation of the value of the national currency". The BM interpreted this mandate as aiming to promote price stability, apparently on grounds that stable inflation is conducive to stable currency. However, the same objective opened room for alternative interpretations, including that the BM was seeking to target the level or variation of the exchange rate, which would contradict with Mozambique's de jure "floating" exchange rate regime. Also, the stated objective left it open whether it meant the value of the currency against other currencies, or a basket of goods and services. Regarding operational independence, it is debatable whether the BM enjoyed it. On the positive side, a robust balance-sheet position over the past several years allowed the BM to bear the monetary policy-related costs and thus secure its autonomy to sterilize excess liquidity. However, the provision in the 01/92 Law permitting the $\mathrm{BM}$ to extend direct financing to the Government constrained the BM in insulating itself from government operations. As it became clear in late 2016 and early 2017, this provision forced the BM to monetize the government deficit by a significant amount, negatively offsetting its efforts to contain inflationary pressures.

\section{Principle II: Price Stability as the Primary or Overriding Objective of Monetary Policy}

As noted previously, it was not clear from the 01/92 Law that price stability was the dominant objective of monetary policy. There was ambiguity in this regard. 


\section{Principle III: Central Bank Has a Medium-term Inflation Objective}

The BM did not have an explicit and publicly known numerical inflation objective for the mediumterm, although it sometimes published, but not always explicitly, near-term inflation forecasts. While the Government announced its 5-6 percent medium-term inflation objective in the Five-Year Plan document, it was not clear whether the BM committed to this objective firmly, perhaps because the objective was mostly set by the Government. There are gains to setting the objective through joint consultations between the Government and the central bank (IMF, 2015).

\section{Principle IV: Policy Actions Take into Account Implications for Macroeconomic Activity and Financial Stability}

The Monetary Policy Committee (MPC) reports placed extensive surveillance on macroeconomic indicators, implicitly suggesting that monetary policy decisions did not ignore potential macroeconomic consequences. Also, the BM appeared to appropriately monitor potential financial stability consequences from monetary policy actions, whenever it was justifiable. Financial stability issues were brought into consideration in all MPC reports (including in some post-MPC press conferences) issued since December 2016 through mid-2017 when the BM had to intervene in two collapsing banks. However, this sometimes came at the cost of deviating the public's attention from monetary policy decisions and their relation with inflation, which constitutes the core business central banks.

\section{Principe V: The Central Bank Has a Clear and Effective Operational Framework}

The BM operational framework was clear in the sense that the policy stance was explicitly set and announced in terms of a specific numerical level of the operating target of monetary policy- reserve money ceiling. However, the framework was not effective for two possible reasons. First, the announcement of reserve money ceilings did not facilitate the communication of the policy stance. The relationship between reserve money and inflation was not well understood by the public and the media. As a result, media coverage of MPC reports tended to highlight the decisions related to changes in BM interest rates rather than to the announced reserve money targets, hinting that the former might have been better suited to signal the monetary policy stance. Second, anecdotal evidence suggests that liquidity exchange in the interbank money market did not respond strongly to the monetary policy stance. That is, banks did usually not place surplus liquidity with, or obtain short-term funding from, each other or the central bank at rates that were reasonably stable and predictable.

\section{Principle VI: The Central Bank Has a Transparent Forward-looking Strategy}

Some forward-looking analysis was provided in MPC reports, but it was generally incomplete. On a positive side, policy decisions rightly placed a greater focus on expected, rather than actual, inflationary pressures. However, explicit numerical inflation forecasts were never released in MPC reports except for a few months following October 2016. The reports also lacked a detailed discussion on how the identified risks to the outlook linked to the inflation forecast (more on this later), and what contingency plans were present in the event of materialization of those risks.

\section{Principle VII: Central Bank Communication Is Transparent and Timely}

The MPC reports were issued timely and with regularity, and the MPC meetings were immediately followed by a press conference which helped consolidate monetary policy communications. However, the contents of both the MPC reports and the press conference were not always understood transparently. On the one hand, this reflected possibly excessive economic jargons entailed in BM communications. On the other, it reflected the relatively low level of economics and financial literacy in the Mozambican society, the solution to which does not rely with the BM.

In addition to not being fully aligned with the seven principles discussed above, the reserve money targeting framework performed weakly vis-à-vis IMF program targets and inflation outcomes. For example, during the 2005-2016 period, reserve money and inflation deviations from their targets and projections, respectively, did not evolve as expected in about 60 percent of the cases. This is particularly 
striking in 2009, 2012 and 2014-2015 when inflation was benign despite the overshoot in reserve money ceilings. Similar counterintuitive events were observed in 2008 and 2011 when reserve money was contained below the ceiling, but inflation overshot (Figure 1).

FIGURE 1

\section{DEVIATIONS OF ACTUAL RESERVE MONEY AND AVERAGE INFLATION FROM TARGET/PROJECTION}

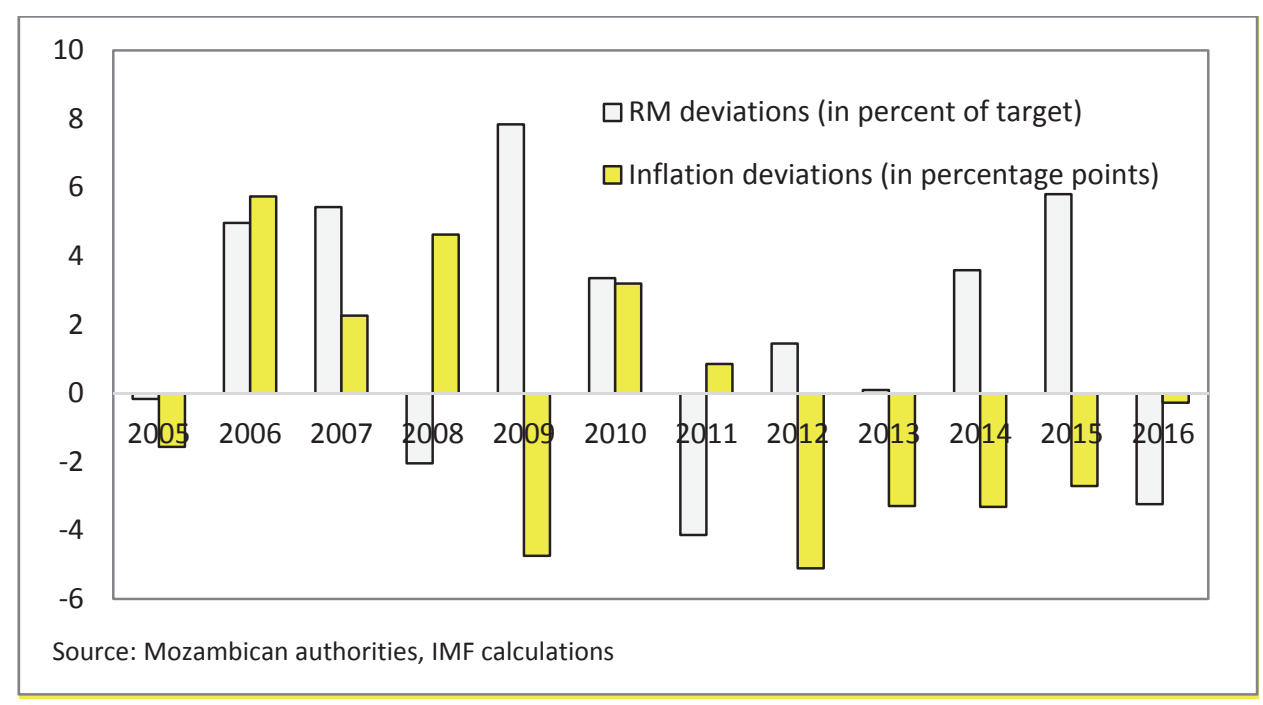

Weak and unstable correlation between monetary aggregates and inflation may have hampered the role of reserve money in anchoring inflation expectations. For example, the contemporaneous correlation coefficient between broad money growth and inflation (month-on-month and year-on-year) is literally zero for the sample 2000M1-2017M6 (Figure 2). Also, the correlation is volatile when looking at different subsamples and, counterintuitively, becomes negative at times, suggesting that the moneyinflation relationship was very unstable (figure not shown in the paper). This is partly explained by recurrent exogenous shocks in Mozambique, although these would be a challenge under any monetary policy regime. 
FIGURE 2

CORRELATION BETWEEN BROAD MONEY GROWTH AND INFLATION (2000M1-2017M6)

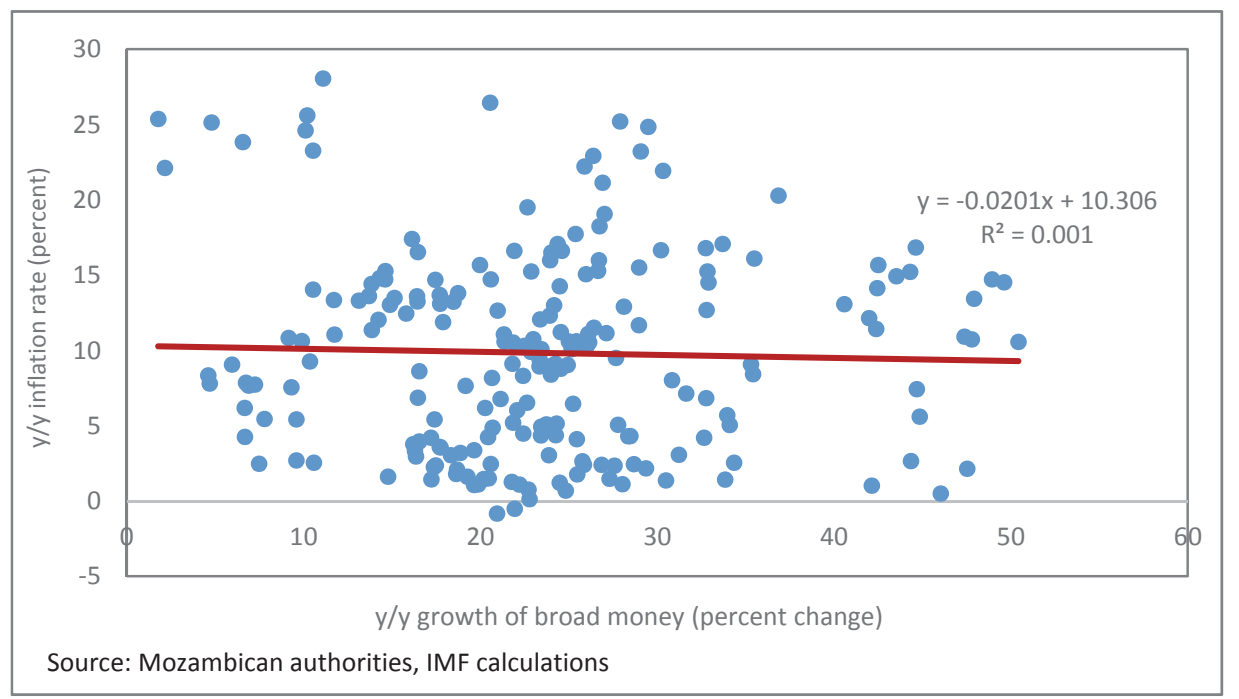

Also, important to note in the same period, the velocity of money remained unstable and declining (Figure 3), challenging the constant velocity assumption implicit in money-based monetary policy frameworks. This meant that reserve money could not be easily forecast, mostly because around half of the reserve money stock comprised currency in circulation, which is extremely sensible to exogenous shocks.

FIGURE 3

VELOCITY OF MONEY (NOMINAL GDP-TO-MONEY RATIO)

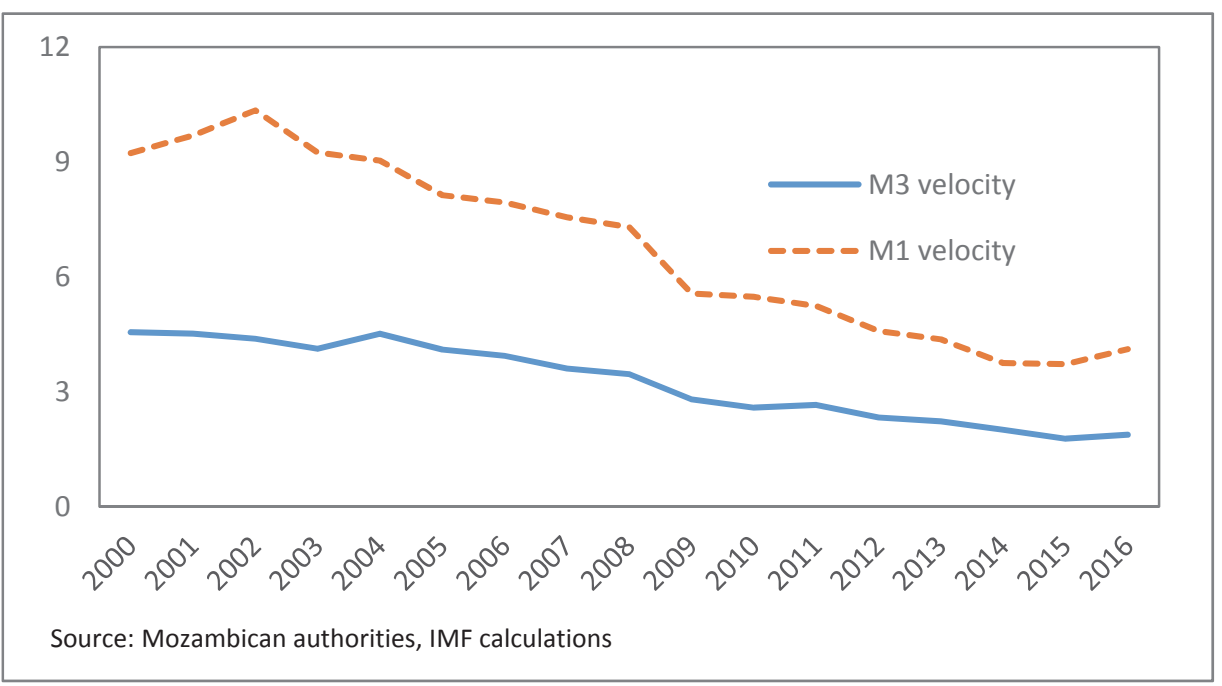

\section{Transition to the New Regime}

The BM is transiting to a new monetary policy regime, in part driven by the challenges discussed above. The need for a stronger monetary policy signal became obvious in 2016 when inflation escalated and became more entrenched, turning the BM's FPC interest rate negative in real terms (Figure 4). In this context, the BM aggressively hiked the FPC by 600 basis points in October 2016. By doing so, the MPC sent an important signal that it was willing to give greater attention to interest rates vis-à-vis reserve 
money, in a clear break with the previous tradition. This remarkable step would pave the way towards the foundation of a new monetary policy regime initiated in April 2017.

\section{FIGURE 4 REAL FPC RATE}

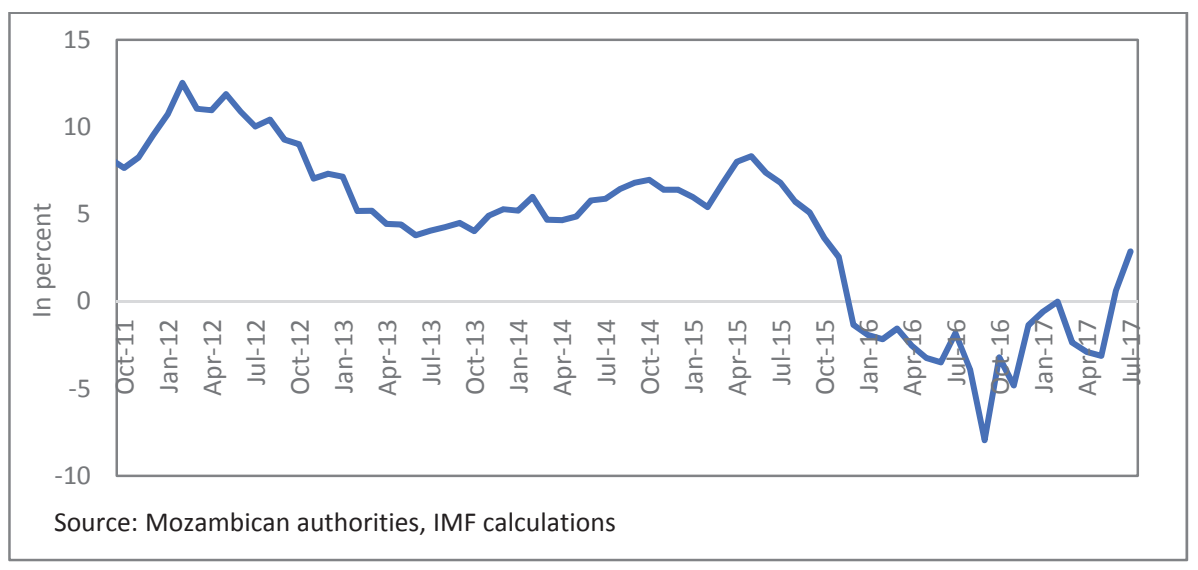

In April 2017, the BM introduced, for the first time, the Reference Monetary Policy Interest Rate (known as MIMO). The MIMO is an overnight interest rate at which the BM intervenes in the interbank market. The interventions are conducted through overnight reverse repos at the MIMO rate with full allotment, thereby aligning overnight secured money market rates closely with the MIMO. It was also expected that the MIMO would help strengthen the interest rate formation mechanism and transparency in the market (Bank of Mozambique, 2017b). While the MIMO is expected to signal the monetary policy stance, the BM continues to monitor monetary aggregates for informational purposes. The introduction of the MIMO rate implicitly recognized the difficulties entailed in communicating the monetary policy stance through reserve money ceilings, but it also somewhat encouraged the public interpretation that the BM will seek to maintain the MIMO rate positive in real terms. In this context, understanding the bimonthly MPC decisions regarding the level of the MIMO rate and the resulting impact on future inflation appears to have gained greater public attention in Mozambique.

Important changes have also been introduced in the foreign exchange and credit markets, which should support the new monetary policy regime. A Reference Exchange Rate was introduced in May 2017 which replaced the multiple exchange rates that were in effect in the market. The new reference rate is based on transactions between commercial banks and their customers, and it is published three times a day in the BM website. In June 2017, the BM introduced, in consultation with commercial banks, the Standardized Prime Interest Rate (Indexante Unico) for banks' lending. Although banks can add a risk spread over this prime rate, it makes banks' final interest rates on loans directly linked to monetary policy decisions. This is because the prime rate is strictly defined as the arithmetic average between the BM's FPC rate and the reverse repo rate plus 600 basis points which have been agreed to represent banks' funding risk. While some argue that the 600 basis points spread may be too high, the Reference Exchange Rate and the Standardized Prime Rate, which are published in the BM website, were important measures to strengthen transparency in the process of exchange rates' and interest rates' formation.

The current regime is de facto a precursor of an inflation targeting regime. BM's recent monetary policy decisions have become more forward-looking, interest-rate based and model-based. Specifically, inflation has emerged more clearly as the final objective of monetary policy and its forecasts are modelbased. The medium-term inflation objective remains 5-6 percent as set by the Government. The MIMO is the operational target signaling the monetary policy stance to achieve the inflation objective. This can be confirmed by a greater emphasis given to inflation expectations in recent MPC reports. Overall, MPC decisions build strongly on the Forecasting and Policy Analysis System (FPAS) like in modern inflation- 
targeting central banks. Monetary aggregates such as reserve money and broad money remain in the BM radar, but as information variables only.

\section{THE WAY FORWARD}

The embryonic monetary regime will often face challenges that will likely test the policy resolve and credibility of the central bank. Building credibility is critical to enable the central bank to effectively signal the monetary policy stance and help anchor inflation expectations. Building capacity to improve inflation forecasting, correctly identifying the monetary policy transmission mechanisms, fostering the development of the interbank market, improving communications, striving for a close coordination with the fiscal authorities, and strengthening the BM legal framework are all essential in the process of building credibility. We discuss each of these challenges next.

\section{Strengthening Forward-looking Capacity}

The new regime's increased focus on inflation as the key monetary policy objective will require enhanced capacity to properly gauge inflation expectations. Further training to develop BM's staff forecasting techniques within the context of the FPAS is of paramount importance. Furthermore, the central bank should develop effective surveys to measure inflation expectations directly, like it is done in most inflation-targeting central banks. At the same time, available interbank market data could be explored to derive complementary proxy indicators of the expected inflation path. Preliminary evidence suggests that the spread between 1-year and 3-month interest rates (i.e., slope of the yield curve) on Tbills could help predict the economic sentiment one quarter ahead. For example, there is a notable relationship between one quarter-lagged slope of the yield curve and the economic confidence indicators compiled by INE (Figure 5). The slope of the yield curve, which can be computed every month, could therefore be a useful variable from which one can gauge the path of aggregate demand and inflation expectations.

\section{FIGURE 5}

\section{CONFIDENCE INDEX AND YIELD CURVE SLOPE}

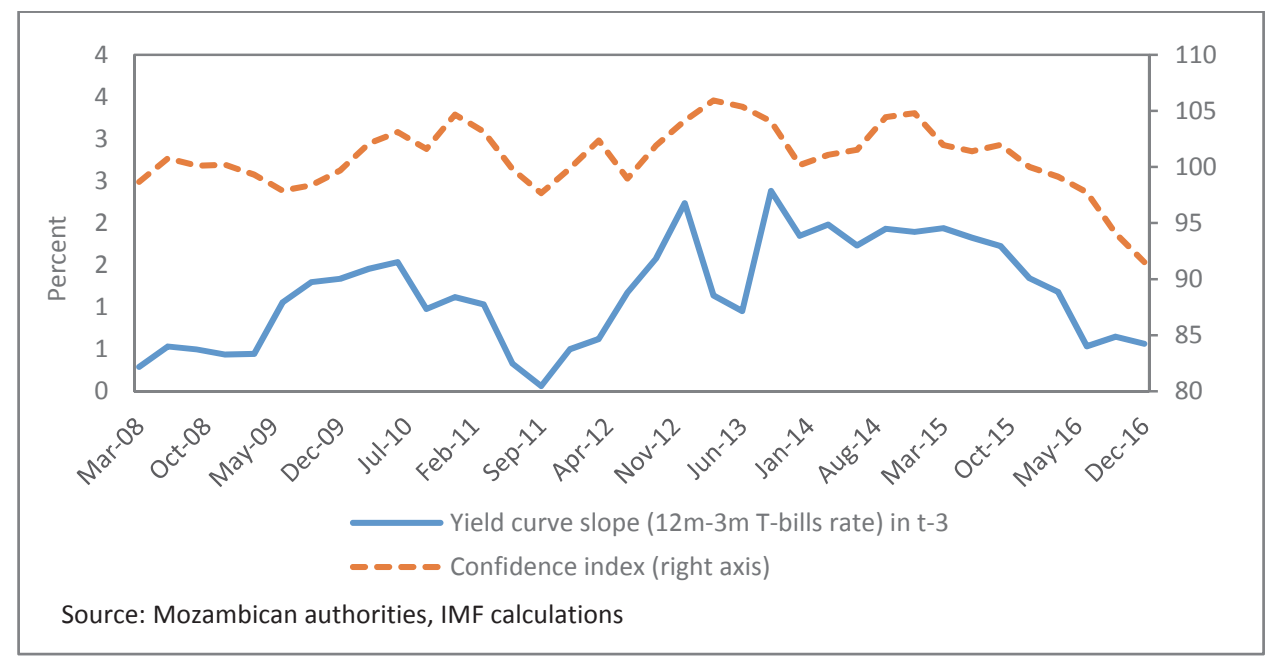

\section{Identifying the Monetary Policy Transmission Mechanisms}

Clear understanding of the channels through which monetary policy shocks impact inflation (i.e., monetary policy transmission channels) remains key. Among the four standard channels- exchange rate, bank lending, interest rate, and asset price channels- the exchange rate channel is probably the most relevant in Mozambique, similarly to other low-income countries. As shown in Appendix 1, changes in 
broad money correlate well with changes in the MT/USD exchange rate (first stage of transmission), and there is also a substantial correlation between exchange rate movements and inflation (final stage of transmission). We do not observe a similar transmission strength as for the banks' lending and interest rate channels. While broad money growth correlates well with credit growth (i.e., the first stage of the transmission is strong), the correlation between banks' credit and inflation (second stage transmission) is weak and does not carry the expected sign.

Finally, broad money growth is weakly negatively correlated with the real interbank lending rate, although there is strong pass-through from the latter to commercial banks' retail lending rates. The arguably weaker transmission of both credit and interest rate channels in affecting inflation could also reflect the existence of a large informal/unbanked economy and a shallow financial market. Moreover, a relatively high degree of dollarization in Mozambique (near 30 percent of banking system deposits are dollarized) could limit the reach of monetary policy to only the domestic-currency denominated assets in the financial sector. ${ }^{5}$ All these factors in principle would also render ineffective the asset price channel. For all these reasons, the exchange rate channel is arguably the most relevant for the conduct of monetary policy in Mozambique. Most of these findings are broadly in line with Mishra and Montiel (2012) in their analysis of LICs.

\section{Dealing with Weak Transmission}

Overall, monetary policy transmission channels are likely to remain weak in the early stages, but should strengthen as Mozambique's financial market structure sophisticates, de-dollarize, and becomes more competitive. As classically argued in Hannan and Berger (1991), weak competition can reduce banks' incentives to react promptly to monetary policy changes, resulting in sluggish interest rate passthrough. An empirical assessment by IMF (2016) finds that, in Mozambique, lower concentration in banks' credits could strengthen the transmission from the central bank reference interest rate to market rates. There is also the need to assess whether the transmission mechanism is asymmetric. Some anecdotal evidence suggests that commercial banks react asymmetrically to changes in monetary policy reference rates, with interest rate increases being more aggressive than cuts. It should be noted that a weak monetary policy transmission does not imply as often (implicitly) argued that monetary policy does not matter and cannot be used to control inflation. The implication is rather that policy actions must be more aggressive to have a meaningful impact.

\section{Promoting a More Active Interbank Market}

The interbank market is an essential link in the monetary policy transmission process. However, in Mozambique it remains incipient in terms of trading. Some anecdotal evidence suggests that banks do not trade actively with each other, even when some banks are short and others are long and thereby generating incentives to trade. This suggests that factors other than market liquidity conditions may also be playing a role in driving banks' incentives to trade. Addressing the barriers to interbank trading will therefore be essential to ensure that the new monetary policy regime is effective.

\section{Improving Communications}

The best a central bank can do is arguably to teach the markets its way of thinking (Blinder, 2004, p. 25). Transiting to a new interest rate-based regime will require that monetary policy decisions are solely grounded on inflation considerations, and that this is well understood by markets and the public. While MPC reports mostly highlight inflation as the main reason underlying policy decisions, the exchange rate is sometimes also emphasized as a reason (Figure 6). It is understandable that the BM is concerned with excessive exchange rate volatility, however policy decisions should not be interpreted as seeking to target the exchange rate. 
FIGURE 6

MAIN REASON FOR MPC DECISIONS

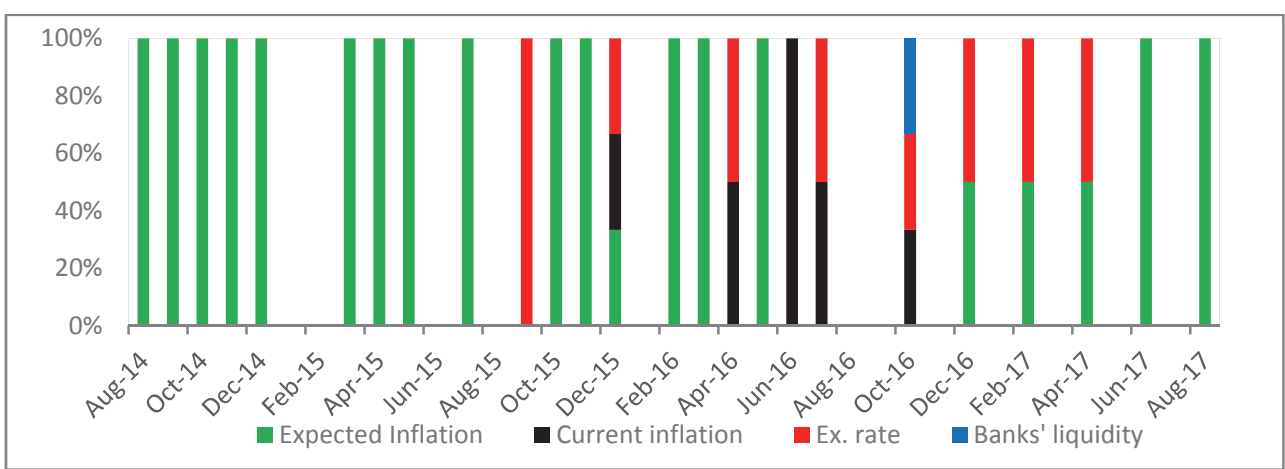

Also, in some cases, prior to 2017, policy decisions put greater emphasis on current, rather than on expected, inflation, which does not help in establishing forward-looking communication. Since December 2016, policy decisions have become solely grounded on expected inflation, which is a positive development. The MPC report had also been publishing explicit medium-term inflation forecasts since October 2016, but this practice has unfortunately been discontinued since June 2017 for unknown reasons. Furthermore, the MPC reports adequately identify risks and uncertainties, with external risks (global prices volatility, world growth, etc.) prevailing the most (Figure 7). However, there is often not a sufficient discussion on how these risks and uncertainties explicitly affect the inflation outlook. Finally, there is the need to separate from the MPC reports any analysis of non-monetary policy issues. Except for August 2017, all MPC reports since December 2016 bring financial stability issues into the analysis, which could interfere with readers' attention to monetary policy decisions.

FIGURE 7

RISKS IDENTIFIED IN THE MPC REPORT

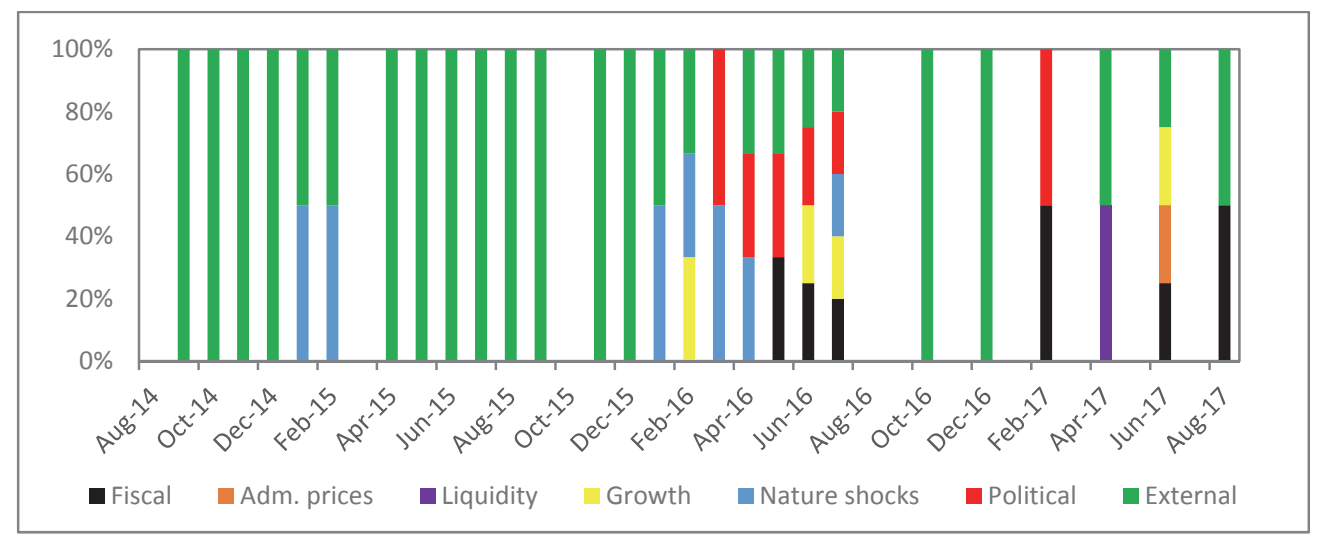

\section{Exchange Rate Targeting Versus Inflation Targeting}

As mentioned in the previous section, the new monetary regime strongly emphasizes the importance of communicating correctly the BM's nominal anchor to the wide public to avoid unintended confusions that could hurt BM's hard-won credibility. Hence, the public should unequivocally understand that the BM will change interest rates only in reaction to the future inflation path. The inflationary impact of exchange-rate variations should obviously be factored in the interest rate decision but should not be targeted at a specific level or rate of change. Ostry et al. (2012) argue that, given the undoubtable importance of the exchange rate for inflation and growth outcomes in LICs, exchange rate intervention 
should be seen as part of the standard monetary policy toolkit in LICs, with interest rates focused mainly on the inflation target and exchange rate intervention focused on the exchange rate target, while recognizing the interactions between these two targets.

Having two targets and two instruments might not be the best alternative. This strategy might be challenging to communicate for an embryonic regime like Mozambique's. Also, targeting the exchange rate would potentially strengthen the hands of those that do not welcome exchange rate movements that could be necessary for reaching inflation objectives. In such circumstances, the central bank would face a huge dilemma, and could risk not handling communications properly to reach both objectives (low and stable inflation, and exchange rate stability). For these reasons, the BM should continue to pursue a freefloating exchange rate regime and limit its foreign exchange intervention solely to reduce excessive exchange rate volatility and building the stock of international reserves. To adequately manage public perceptions about its commitment to target inflation (and not the exchange rate), the BM could preannounce the total and daily volumes and period during which it plans to buy foreign exchange for reserve accumulation.

\section{Monetary and Fiscal Policy Coordination}

Any monetary regime is highly dependent on fiscal discipline and, its absence, could create risks to the credibility of the new monetary regime. Hence, it is of utmost importance to ensure a sound coordination of policies between the BM and the Ministry of Finance. Although there are frequent coordinating meetings between the technical teams of both institutions, focus should be given to four core elements:

1) The Ministry of Finance needs to frequently update the BM on changes to the fiscal policy stance during the budget formulation and execution cycles. This should help the BM to more accurately forecast inflation by appropriately factoring in its medium-term model the effects of the fiscal impulse on aggregate demand. It will also help both institutions to plan the calendar of issuances of Treasury Bonds with the Stock Market and Treasury Bills at the BM that should ideally be transparently published at the BM website ahead of time and remain unchanged to increase its credibility and reduce financing costs.

2) The Treasury should inform the BM on a weekly basis about its liquidity needs. This would help the BM anticipate any needed change in the volumes of T-bills to be issued vis-à-vis the planned issuances in the calendar and controlling the impact of fiscal policy on the overall market liquidity. This would require the use of other instruments (repos and reverse repos) to sterilize the shortage and excess liquidity to ensure the interbank rate stays closely aligned to the MIMO rate.

3) A strong policy coordination should help ensure that Treasury's use of liquidity at the overdraft facility at the BM should be restricted to only exceptional circumstances. Both institutions should agree on access with annual amounts tied to expected annual Treasury's revenue and strict repayment terms (interest rate and time of repayment) to encourage prudent fiscal management and avoid unduly increasing market liquidity. It must be agreed that any impact of fiscal operations on liquidity should be quickly sterilized. These changes can be enshrined in the BM's Organic Law to avoid the recurrence of the recent large use of the BM's overdraft facility by the BM.

4) Institutional coordination requires that the Ministry of Finance supports the BM in paying for the monetary policy-related costs. The BM should have ample access to marketable instruments and flexibility to use them as needed in its sterilization operations free from cost considerations. The final impact of these operations on BM's income statement may potentially imply that the BM will not be able to pay dividends to the Treasury. Moreover, both institutions should help ensure that the BM's capital represents a sufficient buffer (as a share of BM's liabilities) to sustain BM's credibility and room for maneuver. Conversely, the BM should be efficiently managed and its management committed to reign on the nonmonetary policy costs. External and internal audit functions should be strengthened by the 
appointment of independent Board members to ensure solid oversight of Management operations.

\section{Reforming the BM Law}

Addressing all the challenges discussed above will require modernizing the legal framework which should at least provide the BM a clear mandate, operational autonomy, and adequate external oversight. As noted earlier, BM's mandate is unclear. As recommended by previous IMF technical assistance missions, the BM should have a clear primary objective to achieve and maintain price stability. The BM mandate is also imprecise as it mixes together objectives and functions. As well as maintaining the value of the metical, the other statutory purposes of BM include conducting monetary policy in a correct manner; to guide the credit policy to promote economic growth and economic and social development; to manage the external reserves to maintain an adequate volume of resources for foreign trade; and to control the banking activity. However, conducting monetary and credit policy, managing foreign reserves, and supervising banks are central bank functions, not objectives. Treating these functions as objectives could cause interpretative difficulties in case of conflicts between different policy targets. Finally, the provision in the law allowing the BM to lend to the Government above the statutory limit should be abolished as it may lead to monetary financing of fiscal deficits. One of the shortcomings of this provision is that the loans may be granted free of interest. If misused, this permission has the potential to undermine the central bank's quest for monetary stability and autonomy (IMF, 2016b).

Overtime, the new monetary regime can help the BM overcome some of the constrains highlighted above. The new regime can improve policy signaling and, through constantly enhancing communication and transparency, help deep capital markets (including the interbank market), strengthen bank competition, enhance monetary-fiscal policy coordination, and even help build momentum for modernizing the legal framework supporting BM's operational autonomy. All these improvements can surely gradually contribute to a sounder and more efficient monetary policy transmission mechanism.

\section{CONCLUSIONS}

BM's transition towards a new interest rate-based and inflation-anchored monetary policy regime is welcome, but it should take into account several considerations. They include the need to improve the forward-looking capacity, particularly regarding expected inflation. Some data is available at BM which could allow its staff to develop tentative market-based yield curves from which inflation expectations could be gauged. This could be complemented by also developing a direct survey on inflation expectations. Consideration should also be given to the monetary policy-inflation transmission mechanisms.

The exchange rate channel appears to be the most relevant transmission mechanism in the Mozambican context. However, the BM should neither take this as a reason to target a level of exchange rate variation as it appeared to be the case in some past events, nor as justifying exchange rate interventions to control inflation. The effectiveness of the new regime will also require a well-functioning interbank market, which could be achieved by identifying and minimizing the barriers that prevent banks to trade actively among each other. Reforms in all these areas should build on an enhanced communication of monetary policy and a reformed BM Law.

Regarding communications, the MPC report should place exclusive focus on the expected inflation, and not on the exchange rate or other variables, as the main reason driving its decisions. It should seek to explain, rather than list, how the materialization of the various risks identified in the report would impact on the inflation forecast. More importantly, the report should disclose explicitly the inflation forecasts, a practice which was discontinued since June 2017 for unknown reasons. In addition, there is the need to exclude from the MPC reports any analysis of non-monetary policy issues (e.g. financial stability issues, as it was the case with most reports in the first half of 2017) as this could interfere with readers' attention to monetary policy decisions. 
An effort to tighten the coordination between fiscal and monetary policies is essential for the success of the new monetary regime and require mutual understanding on the needs of the BM to excel in its objective to keep inflation low and stable. Regarding the BM Organic Law, it should be reformed to give the BM a clear primary objective to achieve and maintain price stability. It should also distinguish better between central bank objectives and functions as this could otherwise cause interpretative difficulties in case of conflicts between different policy targets.

Finally, the provision in the law allowing the BM to lend to the government above the statutory limit should be abolished as it may lead to monetary financing of fiscal deficits, ultimately undermining the central bank's quest for monetary stability and autonomy. The good news is that the BM has strong technical teams and a committed management, all of which should help implement the needed reforms supportive of the new regime.

\section{REFERENCES}

Bank of Mozambique. (2017). Desafios da Modernização do Regime da Política Monetária: O Caso de Moçambique.

Berg, A., Charry, L., Portillo, R., \& Vlcek, J. (2013). The Monetary Transmission Mechanism in the Tropics: A Narrative Approach. IMF Working Paper WP/13/197.

Blinder, A. S. (2004). The Quiet Revolution: Central Banking Goes Modern. New Haven, CN: Yale University Press.

Comite de Politica Monetaria, Comunicado 02/2017. (2017b).

Hannan, T., \& Berger, A. (1991, September). The Rigidity of Prices: Evidence from the Banking Industry. The American Economic Review, 81(4), 938-945.

International Monetary Fund. (2015). Evolving Monetary Policy Frameworks in Low-Income and Other Developing Countries. Staff Report (Washington: International Monetary Fund).

Mishra, P., \& Montiel, P. J. (2013). How Effective Is Monetary Transmission in Low-Income Countries? A Survey of the Empirical Evidence. Economic Systems, 37(2), 187-216.

Mishra, P., \& Montiel, P. J., \& Spilimbergo, A. (2012). Monetary Transmission in Low-Income Countries: Effectiveness and Policy Implications. IMF Economic Review, (60), 270-302.

Ostry, J. D., Ghosh, A. R., \& Chamon, M. (2012). Two Targets, Two Instruments: Monetary and Exchange Rate Policies in Emerging Market Economies. IMF Staff Discussion Note, 12/01.

República de Moçambique. Assembleia da República, Lei nº. 01/92

Safeguards Assessments Mission. (2016). Aide-Mémoire.

Selected Issues. (2016). IMF Country Report, 16/10. 


\section{APPENDIX 1}

CHANNELS OF MONETARY POLICY TRANSMISSION, JANUARY 2002-JUNE 2017

Changes in broad money vs. MT/USD exchange rate

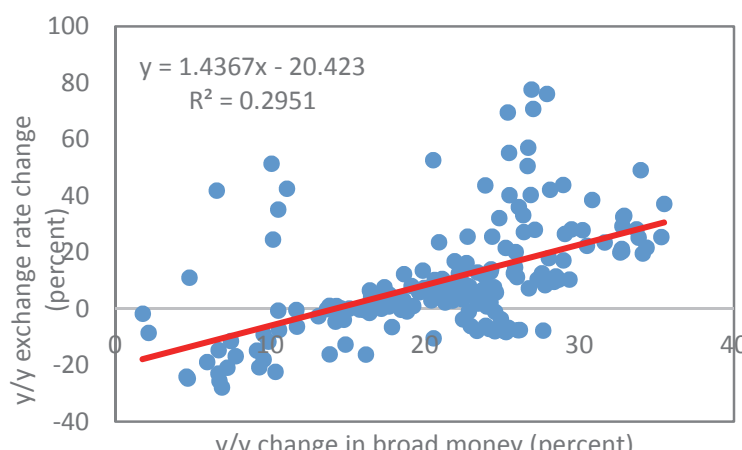

Changes in broad money vs. banks' credit

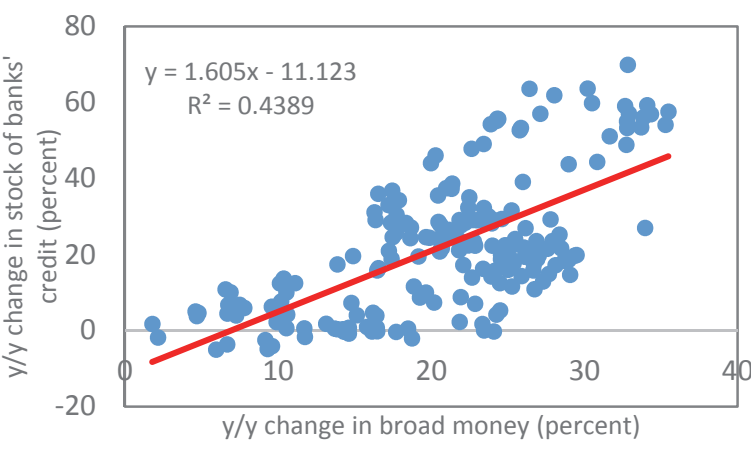

Changes in broad money vs. interbank real lending interest rate

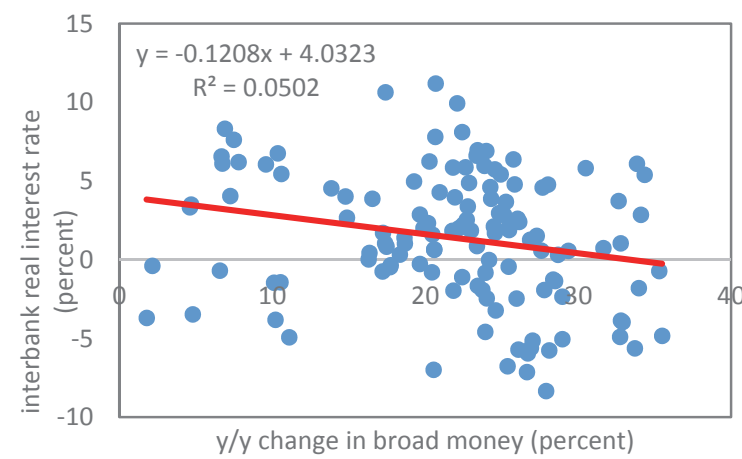

Changes in the MT/USD exchange rate vs. inflation

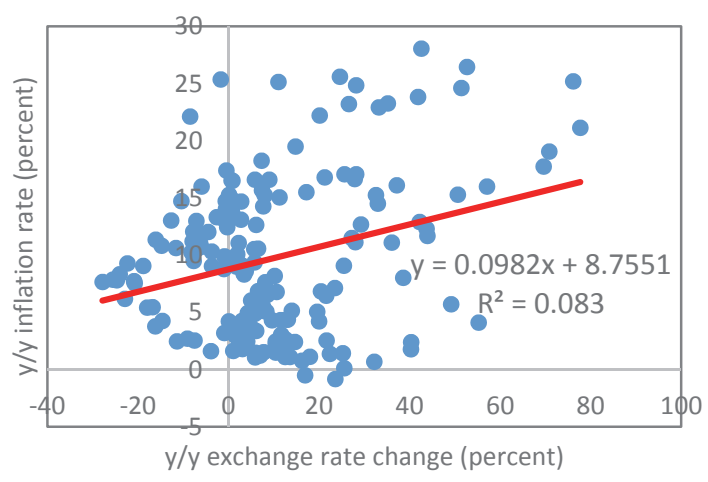

Changes in banks' credit vs. inflation

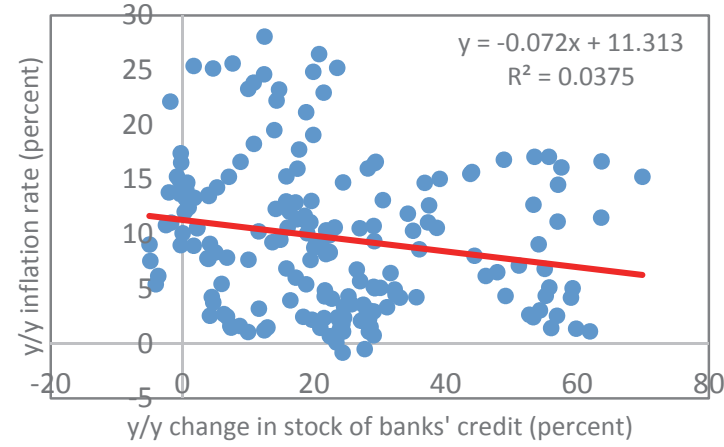

Interbank vs. retail lending interest rates

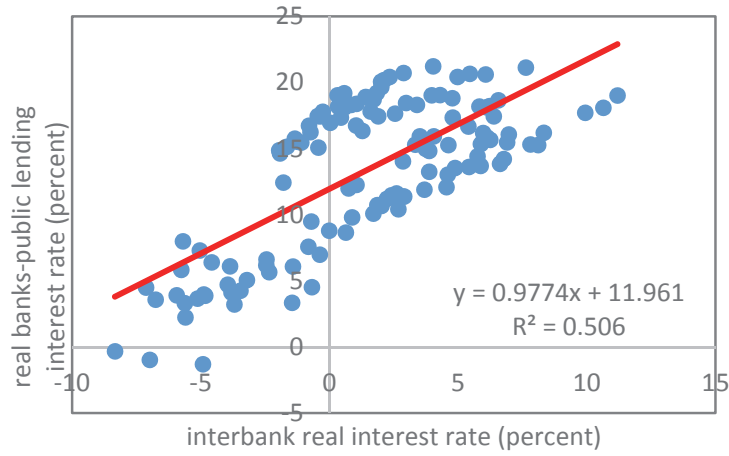

Source: Mozambican authorities, IMF calculations

Note: The sample period for the last two charts is 2006M12-2017M6. 